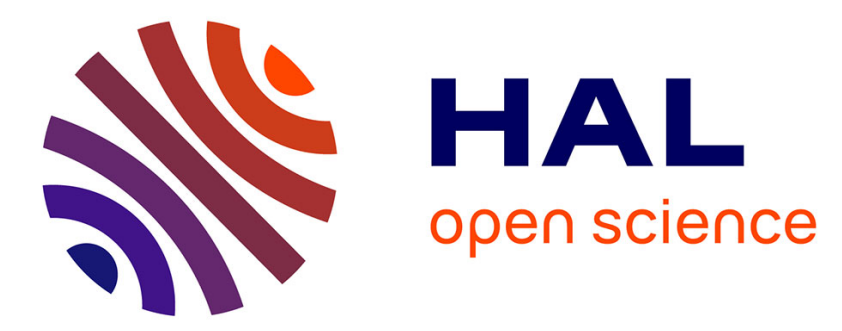

\title{
Chemical Delivery System of MIBG to the Central Nervous System: Synthesis, 11 C-Radiosynthesis, and in Vivo Evaluation
}

Fabienne Gourand, Delphine Patin, Axelle Henry, Meźiane Ibazizeǹe, Martine Dhilly, Fabien Fillesoye, Olivier Tirel, Mihaela-Liliana Tintas, Cyril

Papamicael, Vincent Levacher, et al.

\section{To cite this version:}

Fabienne Gourand, Delphine Patin, Axelle Henry, Meźiane Ibazizeǹe, Martine Dhilly, et al.. Chemical Delivery System of MIBG to the Central Nervous System: Synthesis, 11 C-Radiosynthesis, and in Vivo Evaluation. ACS Medicinal Chemistry Letters, 2019, 10 (3), pp.352-357. 10.1021/acsmedchemlett.8b00642 . hal-03020265

\section{HAL Id: hal-03020265 https://hal.science/hal-03020265}

Submitted on 23 Nov 2020

HAL is a multi-disciplinary open access archive for the deposit and dissemination of scientific research documents, whether they are published or not. The documents may come from teaching and research institutions in France or abroad, or from public or private research centers.
L'archive ouverte pluridisciplinaire HAL, est destinée au dépôt et à la diffusion de documents scientifiques de niveau recherche, publiés ou non, émanant des établissements d'enseignement et de recherche français ou étrangers, des laboratoires publics ou privés. 


\title{
, Chemical Delivery System of MIBG to the Central Nervous System: Synthesis, ${ }^{11} \mathrm{C}$-Radiosynthesis, and in Vivo Evaluation
}

\author{
3 Fabienne Gourand, ${ }^{*}+\underset{+}{*}$ Delphine Patin, ${ }^{\ddagger}$ Axelle Henry, ${ }^{\dagger}$ Méziane Ibazizène, ${ }^{\ddagger}$ Martine Dhilly, \\ ${ }_{4}$ Fabien Fillesoye, ${ }^{\ddagger}$ Olivier Tirel, ${ }^{\ddagger}$ Mihaela-Liliana Tintas, ${ }^{\ddagger}$ Cyril Papamicaël, ${ }^{\dagger}$ Vincent Levacher, $*{ }^{\dagger}{ }^{\dagger}$ \\ $s$ and Louisa Barrét
}
$6{ }^{*}$ Normandie Univ, UNICAEN, CEA, CNRS, UMR 6030 ISTCT/LDM-TEP group, Bd Henri Becquerel, BP 5229, 14074 Cedex
7 Caen, France
$8{ }^{\dagger}$ Normandie Univ, COBRA, UMR 6014 et FR 3038; Univ Rouen; INSA Rouen; CNRS, IRCOF, 1 rue Tesnière, 76821 Mont Saint
9 Aignan Cedex, France

10 S Supporting Information

11 ABSTRACT: The norepinephrine transporter (NET) plays an impor12 tant role in neurotransmission and is involved in a multitude of 13 psychiatric and neurodegenerative diseases. $\left[{ }^{123} \mathrm{I} /{ }^{131} \mathrm{I}\right]$ meta-iodobenzyl14 guanidine (MIBG) is a widely used radiotracer in the diagnosis and 15 follow-up of peripheral neuroendocrine tumors overexpressing the 16 norepinephrine transporter. MIBG does not cross the blood-brain 17 barrier (BBB), and we have demonstrated the "proof-of-concept" that 1,418 dihydroquinoline/quinolinium salt as chemical delivery system (CDS) is 19 a promising tool to deliver MIBG to the brain. To improve BBB passage, 20 various substituents on the 1,4-dihydroquinoline moiety and a linker 21 between CDS and MIBG were added. A series of CDS-MIBGs 1a-d was synthesized, labeled with carbon-11, and evaluated in vivo into rats. The in vivo results demonstrated that, although adding substituents on CDS in $1 \mathrm{a}-\mathrm{c}$ is of no benefit for brain delivery of MIBG, the presence of a linker in CDS-MIBG 1d greatly improved both brain penetration and the release rate of MIBG in the central nervous system.

KEYWORDS: Central nervous system, norepinephrine transporter, MIBG, radiosynthesis, redox chemical delivery system, 1,4-dihydroquinolines carriers
${ }_{27} \Gamma$ he in vivo expression of norepinephrine transporter 28 (NET) is mostly established in the central and peripheral 29 sympathetic nervous system. Several different radiotracers for 30 clinical imaging of NET expression were developed.

31 Among them, meta-iodobenzylguanidine (MIBG) is struc32 turally similar to the neurotransmitter norepinephrine, and $33\left[{ }^{123} \mathrm{I}\right]$ MIBG single photon emission computed tomography 34 (SPECT) imaging studies are the most accurate method for 35 detection of catecholamine-secreting tumors including neuro36 endocrine tumors such as pheochromocytoma and neuro37 blastoma. $^{1-3}$

38 Moreover, MIBG was also radiolabeled with iodine-131 for 39 radiotherapy to treat neuroendocrine tumors. Positron 40 emission tomography (PET) is more accurate and has the 41 potential to be more sensitive and to provide better image 42 resolution. In this context, efforts to develop MIBG analogs 43 labeled with a positron emitter remain of great interest, and 44 several ${ }^{18} \mathrm{~F}$-labeled benzylguanidine analogs have already been 45 developed for PET imaging of NET expression. Recently, the 46 radiotracer meta- $\left[{ }^{18} \mathrm{~F}\right]$ Fluorobenzylguanidine ( $\left.\left[{ }^{18} \mathrm{~F}\right] \mathrm{MFBG}\right)$ 47 has shown to be a very promising PET candidate leading to 48 successful clinical investigations. ${ }^{4-7}$ Dysregulation of NET is 49 implicated in various neuropsychiatric disorders such as depression, anxiety, attention deficit hyperactivity disorders 50 (ADHD), Parkinson's disease, Alzheimer's disease, and 51 epilepsy. As the NET plays an important role in the central 52 nervous system (CNS), the use of MIBG or MIBG analogs in 53 brain imaging needs to be explored. However, MIBG is unable 54 to cross the blood-brain-barrier (BBB). Guilloteau et al. have 55 compared the uptake and release of radioiodinated meta- 56 iodobenzylguanidine ([$\left.\left.{ }^{125} \mathrm{I}\right] \mathrm{MIBG}\right)$ and tritiated norepinephr- 57 ine $\left(\left[{ }^{3} \mathrm{H}\right] \mathrm{NE}\right)$ in different regions of the rat brain. The authors 58 found comparable regional distribution of $\left[{ }^{3} \mathrm{H}\right] \mathrm{NE}$ and 59 $\left[{ }^{125} \mathrm{I}\right] \mathrm{MIBG}$ uptake in the rat brain. ${ }^{8} \mathrm{~A}$ chemical delivery 60 system (CDS) designed for MIBG able to cross the BBB would 61 provide a potential imaging marker to visualize the NET in the 62 brain (Figure 1). In the literature, Bodor et al. have developed $63 \mathrm{fl}$ an interesting CDS based on a lipophilic 1,4-dihydropyridine 64 able to cross the lipophilic BBB. ${ }^{9,10}$ Then, the 1,4- 65 dihydropyridine system is oxidized into the CNS to a 66 hydrophilic pyridinium species. which cannot cross back the 67 BBB (named as "the locked in effect"). A subsequent 68

Received: December 18, 2018

Accepted: February 15, 2019

Published: February 15, 2019 
Blood BBB Brain

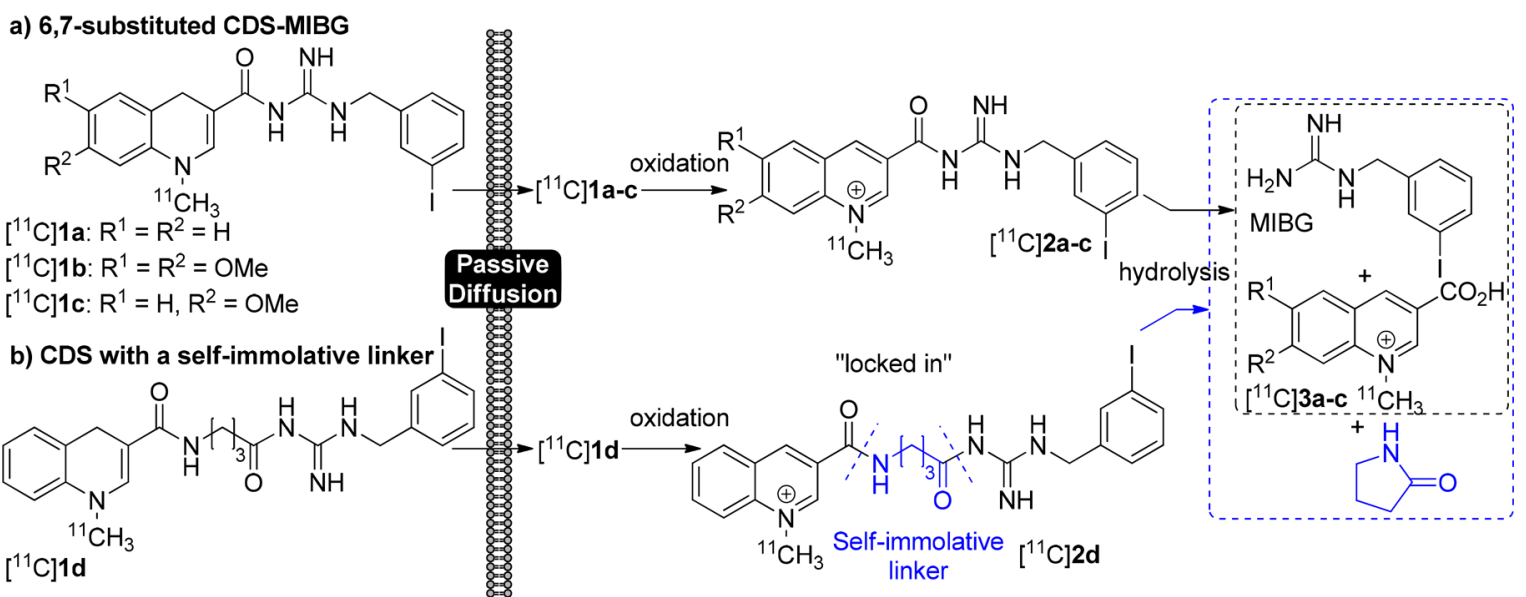

Figure 1. Development of a ${ }^{11} \mathrm{C}$-chemical delivery system of MIBG into the CNS.

69 hydrolysis releases the active compound, which can then act 70 directly on the target into the CNS. By using this approach, 71 Bodor et al. have targeted many drugs to the CNS. ${ }^{11-14}$ Later, 72 Levacher et al. have solved many drawbacks related to this 73 CDS by means of 1,4-dihydroquinolines instead of 1,474 dihydropyridines. However, although mainly drugs were 75 successfully targeted using this strategy, very few reports deal 76 with the use of this CDS to target radiotracers into the brain. A 77 survey of the literature indicated that, aside from our previous 78 work on MIBG, ${ }^{15,16}$ only a single research article ${ }^{17}$ explored 79 the potential of this appealing CDS approach to deliver a 80 radiolabeled agent into the CNS. As far as our preliminary 81 research work on MIBG is concerned, our initial work focused 82 on the radiolabeling with carbon- 11 of the CDS in order to 83 validate the concept described previously. The results of the in 84 vivo studies were highly encouraging, supporting our working 85 hypothesis that the dihydroquinoline system may possibly be a 86 promising CDS to target MIBG to brain tissues. Indeed, after 87 in vivo injection into rats of $\left[{ }^{11} \mathrm{C}\right] \mathrm{CDS}-\mathrm{MIBG}\left(\left[{ }^{11} \mathrm{C}\right] \mathbf{1 a}\right)$, the 88 passage of $\left[{ }^{11} \mathrm{C}\right] \mathbf{1 a}$ through the $\mathrm{BBB}$ has been demonstrated as 89 well as the presence of MIBG in the brain. However, this 90 chemical delivery system has some limitations: (1) a moderate 91 brain penetration has been measured, and (2) the oxidation 92 kinetics of $\left[{ }^{11} \mathrm{C}\right] 1 \mathrm{1a}$ was quite slow since more than $50 \%$ was 93 still present in rat brain at $45 \mathrm{~min}$ post injection. For these 94 reasons, this CDS still needed to be optimized before being 95 applied to radioiodinated MIBG. This Letter will focus on the 96 preparation and in vivo evaluation of new 1,4-dihydroquino97 line-MIBG systems $\left[{ }^{11} \mathrm{C}\right] \mathbf{1 b}, \mathrm{c}$ bearing methoxy groups to tune 98 the redox potential of the CDS. The preparation and in vivo 99 evaluation of a 1,4-dihydroquinoline $\left[{ }^{11} \mathrm{C}\right] \mathbf{1 d}$ having a self100 immolative linker between the CDS and MIBG will be also 101 reported (Figure 1).

102 To perform the radiosynthesis and in vivo study of our 103 systems, it was first necessary to synthesize the precursors for 104 radiolabeling and references that will be used to identify 105 compounds in radio-HPLC. We have previously described the 106 synthesis of the targeting system 1a starting from quinoline 4a 107 (Scheme 1). ${ }^{15}$ We decided to adopt the same approach to 108 prepare $\mathbf{1 b}, \mathbf{c}$. Thus, a coupling reaction from quinolines $109 \mathbf{4 b}, \mathbf{c}^{18,19}$ and MIBG using CDI led to the corresponding 110 quinolines $\mathbf{5 b}, \mathbf{c}$ in moderate yields (36\% and $30 \%$, 111 respectively). Alternatively, quinoline $5 \mathrm{c}$ could be prepared
Scheme 1. Synthesis of the Redox CDS-MIBG $1 a-c^{a}$

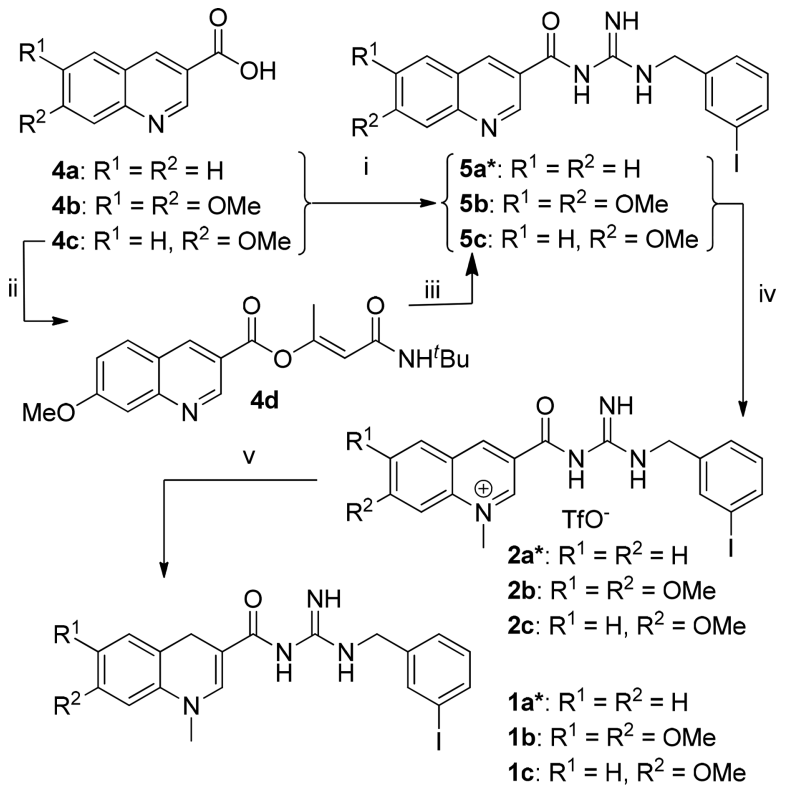

${ }^{a}$ Reagents and conditions: (i) CDI, DMF, $20{ }^{\circ} \mathrm{C}, 1 \mathrm{~h}$ then MIBG, 20 ${ }^{\circ} \mathrm{C}, 1 \mathrm{~h}$ for $\mathbf{5 a *}(60 \%)$ and $\mathbf{5 b}(36 \%)$ and $\mathbf{5 c}(30 \%)$; (ii) NBI, $\mathrm{NEt}_{3}$, DMF, $20{ }^{\circ} \mathrm{C}, 12 \mathrm{~h}$ (74\%); (iii) MIBG, DMF, $140{ }^{\circ} \mathrm{C}, 7 \mathrm{~h}(76 \%)$; (iv) $\mathrm{CH}_{3} \mathrm{OTf}, \mathrm{CH}_{2} \mathrm{Cl}_{2}, 20{ }^{\circ} \mathrm{C}, 2 \mathrm{~h}$ for $\mathbf{2 a} *(50 \%), 3 \mathrm{~h}$ for $\mathbf{2 b}(60 \%)$ and $\mathbf{2 c}$ (81\%); (v) BNAH, $\mathrm{CH}_{2} \mathrm{Cl}_{2}, 20^{\circ} \mathrm{C}, 12 \mathrm{~h}$ for $\mathbf{1 a} *(95 \%), \mathbf{1 b}(32 \%), \mathbf{l c}$ $(70 \%) . \mathbf{1} a^{*}, \mathbf{2} a *$ and $\mathbf{5 a *}$ results are from ref 15 .

by reacting MIBG with the activated enol ester ${ }^{20} 4 \mathbf{d}(76 \%), 112$ the latter having been obtained by reacting $4 \mathrm{c}$ with NBI (74\%). 113 Then, quinolines $\mathbf{5 b}, \mathbf{c}$ were easily transformed into their 114 corresponding quinolinium salts $\mathbf{2 b}, \mathbf{c}$ (60\% and $81 \%, 115$ respectively) in the presence of methyl triflate. Finally, the 116 desired CDS-MIBG $\mathbf{1 b}, \mathbf{c}$ were successfully obtained after 117 regioselective reduction of quinolinium salts $\mathbf{2} \mathbf{b}, \mathbf{c}$ by means of 118 BNAH (32\% and 70\%, respectively).

119

We next turned our attention to the synthesis of a CDS 120 having a $\gamma$-aminobutyric acid (GABA) self-immolative linker 121 group. ${ }^{21-23}$ We envisaged the synthesis of quinoline 9 from 122 GABA derivative $6 \mathbf{a}$ (Scheme 2, route A). So, neutralization of $123 \mathrm{~s} 2$ hydrochloride amine salt $\mathbf{6 a}$ and subsequent coupling reaction 124 with carboxylic acid 4a using BOP reagent led to quinoline 7 a 125 
Scheme 2. Initial Routes To Synthesize the Targeting System $1 \mathrm{~d}^{a}$

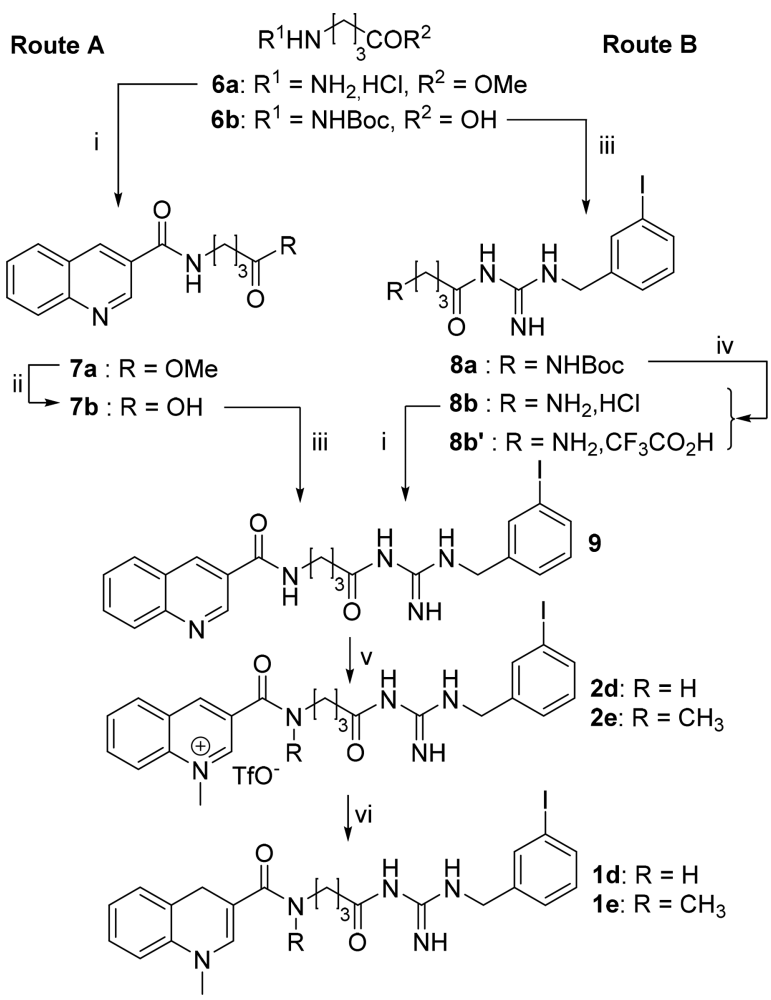

${ }^{a}$ Reagents and conditions: (i) $\mathrm{NaOH}$ then $4 \mathrm{a}, \mathrm{BOP}, \mathrm{NEt}_{3}, \mathrm{DMF}, 20$ ${ }^{\circ} \mathrm{C}, 12 \mathrm{~h}$ (79\% for $7 \mathrm{a}, 25 \%$ for 9); (ii) $\mathrm{LiOH}, \mathrm{THF}, \mathrm{MeOH}, \mathrm{H}_{2} \mathrm{O}, 20$ ${ }^{\circ} \mathrm{C}, 3 \mathrm{~h}$ (96\%); (iii) BOP, MIBG, NEt 3 , DMF, $20{ }^{\circ} \mathrm{C}, 12 \mathrm{~h}$ (25\% for 8a, $4 \%$ for 9); (iv) $\mathrm{CH}_{3} \mathrm{COCl}, \mathrm{MeOH}, 20{ }^{\circ} \mathrm{C}, 1 \mathrm{~h}$ for $\mathbf{8 b}(95 \%)$ or TFA, $\mathrm{CH}_{2} \mathrm{Cl}_{2},-5{ }^{\circ} \mathrm{C}, 1 \mathrm{~h}$ for $\mathbf{8 b ^ { \prime }}(98 \%)$; (v) $\mathrm{CH}_{3} \mathrm{OTf}, \mathrm{CH}_{2} \mathrm{Cl}_{2}, 20$ ${ }^{\circ} \mathrm{C}, 12 \mathrm{~h}$ (44\% for $2 \mathrm{~d}$ and $23 \%$ for $2 \mathrm{e}$ determined by ${ }^{1} \mathrm{H}$ NMR); (vi) $\mathrm{BNAH}, \mathrm{CH}_{2} \mathrm{Cl}_{2}, 20{ }^{\circ} \mathrm{C}, 12 \mathrm{~h}$.

126 (79\% yield). The methyl ester functional group was hydrolyzed 127 by $\mathrm{LiOH}$ to give carboxylic acid $7 \mathbf{b}$ ( $96 \%$ yield). The latter was 128 subsequently involved in a coupling reaction with MIBG using $129 \mathrm{BOP}$ to give 9 in a very low yield (4\% yield). We also 130 investigated other activation strategies of carboxylic acid $7 \mathbf{b}$ by 131 means of CDI, ClCOOEt, (COCl), NBI, or NHS/DCC. 132 Unfortunately, we failed to obtain 9 by using these reagents. 133 Alternatively, $N$-protected GABA $\mathbf{6} \mathbf{b}$ and MIBG were reacted 134 in the presence of BOP reagent to furnish the coupling product $1358 \mathrm{a}$ in $25 \%$ yield (Scheme 2, route B). Then, $N$-Boc 136 deprotection was carried out by using either acetyl chloride/ $137 \mathrm{MeOH}$ or TFA to lead, respectively, to the desired ammonium 138 salts $\mathbf{8 b}$ and $\mathbf{8} \mathbf{b}^{\prime}$ (95\% and $98 \%$ yields). One may note that 20 139 equiv of acetyl chloride/ $\mathrm{MeOH}$ or TFA were required during 140 the course of the $N$-Boc deprotection to prevent from the 141 formation of the undesired $\gamma$-lactam ring resulting from the 142 cyclization reaction of the self-immolative linker. Thereafter, 143 ammonium 8b was neutralized back to $\mathrm{pH} 7$ with sodium 144 hydroxide before being converted into the desired amide 9 in $14525 \%$ yield by means of a coupling reaction between $4 a$ and 146 BOP reagent. The quaternization reaction of 9 with methyl 147 triflate afforded a mixture of $\mathbf{2 d , e}$ ( $44 \%$ and $23 \%$, respectively, 148 estimated by ${ }^{1} \mathrm{H}$ NMR). We then proceeded to a classical 149 reduction of the mixture of quinolinium salts $2 \mathbf{d}, \mathbf{e}$ with BNAH. 150 However, LC/MS analysis of the crude reaction medium 151 revealed the presence of both 1,4-dihydroquinolines $1 \mathrm{~d}, \mathbf{e}$ and quinolinium salts 2 d,e, which turned out to be extremely 152 difficult to separate. Given this result, we decided to explore 153 another route to obtain exclusively 1,4-dihydroquinoline 1d. 154 To overcome the alkylation reaction leading to undesirable 155 compound $2 \mathrm{e}$, quinoline $4 \mathrm{e}$ was first quaternized with methyl 156 triflate to give the key intermediate 10 in $96 \%$ yield (Scheme $157 \mathrm{~s} 3$ $3)$. The resulting NHS-activated quinolinium $\mathbf{1 0}^{24}$ was $158 \mathrm{~s} 3$

Scheme 3. Alternative Route to the Redox CDS-MIBG $1 \mathrm{~d}^{a}$

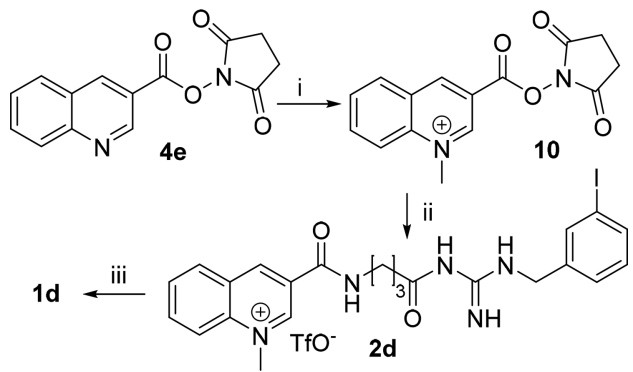

${ }^{a}$ Reagents and conditions: (i) $\mathrm{CH}_{3} \mathrm{OTf}, \mathrm{CH}_{2} \mathrm{Cl}_{2}, 20{ }^{\circ} \mathrm{C}, 4 \mathrm{~h}$ (96\%); (ii) polymer-bound DBU, 8b' $\mathrm{CH}_{2} \mathrm{Cl}_{2}, 20{ }^{\circ} \mathrm{C}, 4 \mathrm{~h}$ (77\% determined by ${ }^{1} \mathrm{H}$ NMR).

smoothly reacted with linker-MIBG derivative $\mathbf{8} \mathbf{b}^{\prime}$ to yield 159 compound 2d (58\%). Finally, a classical reduction reaction 160 with BNAH led to the desired MIBG-targeting system 1d 161 (77\% determined by ${ }^{1} \mathrm{H}$ NMR).

Radiosyntheses of $\left[{ }^{11} \mathrm{C}\right] \mathbf{1} \mathbf{b}, \mathbf{c}$ were carried out as depicted in 163 Scheme 4 according to a two-step synthetic procedure. ${ }^{15,16,25} 164 \mathrm{~s} 4$ The structures of the ${ }^{11} \mathrm{C}$-labeled products were confirmed by 165 comparing their retention time with the corresponding 166 nonradioactive standard compounds using reverse-phase 167 HPLC. Thus, the quaternization reaction of quinolines 5b,c 168 with $\left[{ }^{11} \mathrm{C}\right]$ methyl triflate afforded quinolinium salts $\left[{ }^{11} \mathrm{C}\right] \mathbf{2 b}, \mathbf{c} .169$ Reduction of $\left[{ }^{11} \mathrm{C}\right] \mathbf{2 b}, \mathbf{c}$ was conducted with $\mathrm{BNAH}$ for 5 min 170 at $100{ }^{\circ} \mathrm{C}$ to provide the corresponding 1,4-dihydroquinolines 171 $\left[{ }^{11} \mathrm{C}\right] \mathbf{1 b}, \mathbf{c}$ (respectively, 68\% and $61 \%$ relative percentages 172 determined by radio-HPLC). The same procedure was applied 173 to the radiosynthesis of $\left[{ }^{11} \mathrm{C}\right] \mathbf{1 d}$. However, radio-HPLC 174 analyses demonstrated that $\left[{ }^{11} \mathrm{C}\right] \mathbf{2 d}$ was not stable enough 175 under these high dilution reaction conditions. To circumvent 176 the poor stability of $\left[{ }^{11} \mathrm{C}\right] \mathbf{2 d}$, we decided to add the reducing 177 agent $\mathrm{BNAH}$ and the alkylating agent $\left[{ }^{11} \mathrm{C}\right] \mathrm{CH}_{3} \mathrm{OTf}{ }_{178}$ simultaneously. Then, the reaction mixture was left to react 179 $5 \mathrm{~min}$ at $20{ }^{\circ} \mathrm{C}$. To prevent $\left[{ }^{11} \mathrm{C}\right] \mathbf{1} \mathbf{d}$ from oxidation during the 180 purification step, basic HPLC conditions were required. So, by 181 adding triethylamine in HPLC eluent, 1,4-dihydroquinoline 182 $\left[{ }^{11} \mathrm{C}\right] \mathbf{1 d}$ was obtained with a radiochemical purity of $50 \% 183$ (based on HPLC analysis of the crude product). A 184 TRACERlab FX-MeI and FX-M radiosynthesis module was 185 used to achieve a fully automated radiosynthesis of $\left[{ }^{11} \mathrm{C}\right] \mathbf{1} \mathbf{b}-\mathbf{d} 186$ using a two-step reaction as shown in Scheme 4. The total 187 synthesis time of the fully automated process was approx- 188 imately $50 \mathrm{~min}$. Activity levels in the final product ranged from 189 592 to $814 \mathrm{MBq}$ for $\left[{ }^{11} \mathrm{C}\right] \mathbf{1 b}$; $259-444 \mathrm{MBq}$ for $\left[{ }^{11} \mathrm{C}\right] \mathbf{1 c}$; and 190 148-518 MBq for $\left[{ }^{11} \mathrm{C}\right] \mathbf{1 d}$. The radiochemical purities of 191 $\left[{ }^{11} \mathrm{C}\right] \mathbf{1 b}-\mathbf{d}$ were $>95 \%$.

Then, biological studies were conducted in rats to 193 determine, in vivo, the cerebral penetration through the BBB 194 of the different MIBG-targeting systems $\left[{ }^{11} \mathbf{C}\right] \mathbf{1 b}-\mathbf{d}$ by 195 measuring the radioactivity of the cerebral samples obtained 196 after sacrifice of the animals (Figure 2). Last but not least, we $197 \mathrm{f} 2$ 
Scheme 4. Radiosyntheses of $\left[{ }^{11} \mathrm{C}\right] 1 \mathrm{~b}-\mathrm{d}^{a}$

a) Radiosynthesis of $\left[{ }^{11} \mathrm{C}\right] 1 \mathrm{~b}, \mathrm{c}$

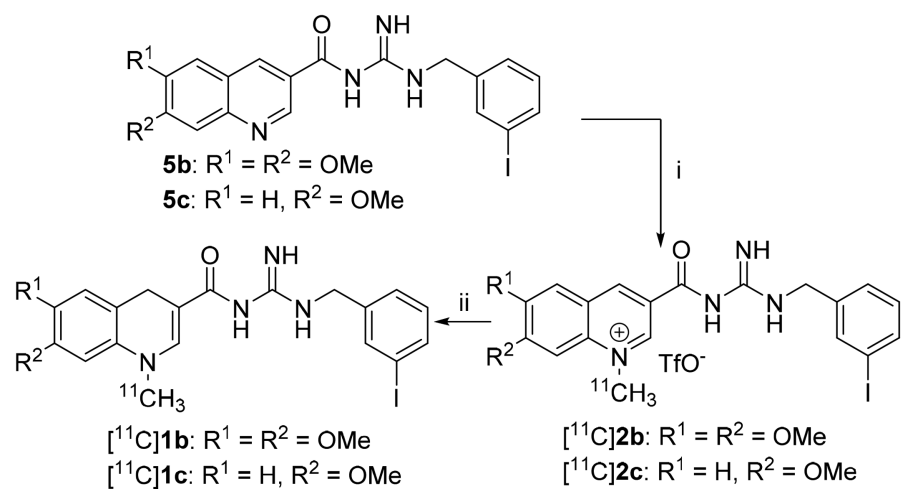

b) Radiosynthesis of $\left[{ }^{11} \mathrm{C}\right] 1 \mathrm{~d}$<smiles>CN1C=C(C(=O)NCC(=O)NC(=N)NCc2cccc(I)c2)Cc2ccccc21</smiles>

${ }^{a}$ Reagents and conditions: for $\left[{ }^{11} \mathrm{C}\right] \mathbf{1 b}, \mathbf{c}$ from $\mathbf{5 b}, \mathbf{c}$ : (i) $\left[{ }^{11} \mathrm{C}\right] \mathrm{CH}_{3} \mathrm{OTf}, \mathrm{CH}_{3} \mathrm{CN}, 20{ }^{\circ} \mathrm{C}, 5 \mathrm{~min}$; (ii) BNAH, $\mathrm{CH}_{3} \mathrm{CN}, 100{ }^{\circ} \mathrm{C}, 5 \mathrm{~min}$; for $\left[{ }^{11} \mathrm{C}\right] \mathbf{1 d}$ from 9: (iii) $\left[{ }^{11} \mathrm{C}\right] \mathrm{CH}_{3} \mathrm{OTf}, \mathrm{CH}_{3} \mathrm{CN}, 20{ }^{\circ} \mathrm{C}$ and $\mathrm{BNAH}$, then $10 \mathrm{~min}, 20{ }^{\circ} \mathrm{C}$.

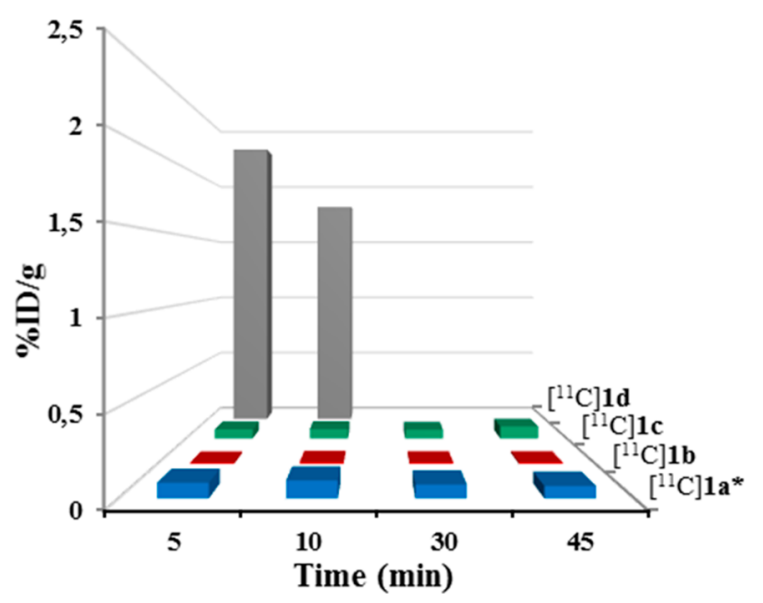

Figure 2. Ex vivo biodistribution of the radioactivity in rat brain at different time intervals following tail vein injection of $\left[{ }^{11} \mathrm{C}\right] \mathbf{1} \mathbf{a}-\mathbf{d}(5$, 10,30 , and $45 \mathrm{~min}$ for $\left[{ }^{11} \mathrm{C}\right] \mathbf{1 a}-\mathbf{c}$; 5 and $10 \mathrm{~min}$ for $\left.\left[{ }^{11} \mathrm{C}\right] \mathbf{1 d}\right)$. Results are expressed in percent of injected dose per gram (\% $\mathrm{ID} / \mathrm{g}$, mean, $n=$ 2 for each point). $\left[{ }^{11} \mathrm{C}\right] 1 \mathrm{a}^{*}$ results are from ref 15 .

198 were also interested (both in brain and plasma) in the 199 oxidation rates of $\left[{ }^{11} \mathrm{C}\right] \mathbf{1} \mathbf{b}-\mathbf{d}$ into the corresponding quinolinium salts $\left[{ }^{11} \mathrm{C}\right] \mathbf{2} \mathbf{b}-\mathbf{d}$, which subsequently led to the 200 cleavage of MIBG from the carrier through hydrolysis. The 201 results will be compared to those already obtained from $\left[{ }^{11} \mathrm{C}\right] 202$ $1 a^{15}$ in order to select the most promising CDS to target 203 MIBG to the CNS.

204

Then, the monitoring of both oxidation and MIBG cleavage 205 steps in the CNS were investigated from brain samples, which 206 were analyzed by radio-HPLC after radiotracer injection. Both 207 CDS-MIBG $\left[{ }^{11} \mathrm{C}\right] \mathbf{1 b}$ and $\left[{ }^{11} \mathrm{C}\right] \mathbf{1 c}$ proved to be rather stable 208 since $87 \%$ and $90 \%$ of 1,4-dihydroquinolines $\left[{ }^{11} \mathrm{C}\right] \mathbf{1} \mathbf{b}, \mathbf{c}, 209$ respectively, were detected at $10 \mathrm{~min}$ after injection, together 210 with $12 \%$ and $5 \%$ of quinolinium salts $\left[{ }^{11} \mathrm{C}\right] \mathbf{2 b}, \mathbf{c}$, respectively, 211 but with no traces of carboxylic acids $\left[{ }^{11} \mathrm{C}\right] 3 \mathrm{~b}, \mathrm{c}$ (Figure $3 \mathrm{~b}, \mathrm{c}$ ). $212 \mathrm{f} 3$ Regarding CDS-MIBG $\left[{ }^{11} \mathrm{C}\right] \mathbf{1}$ a previously investigated, ${ }^{15}$ the 213 percentage of carboxylic acid $\left[{ }^{11} \mathrm{C}\right] 3 \mathrm{a}$ reached $11 \%$ at $10 \mathrm{~min} 214$ after injection, highlighting a faster cleavage of MIBG from the 215 quinolinium salt 2a (Figure 3a). We can therefore draw the 216 conclusion that the presence of methoxy groups on the carrier 217 do not increase the oxidation rates of $\left[{ }^{11} \mathrm{C}\right] \mathbf{1} \mathbf{b}, \mathbf{c}$ in the brain 218 compared to $\left[{ }^{11} \mathrm{C}\right] \mathbf{1 a}$ and even seems to delay the cleavage of 219 MIBG from the resulting quinolinium salts $\left[{ }^{11} \mathrm{C}\right] \mathbf{2 b}, \mathbf{c}$. 220

At this stage, it seems that in terms of brain uptake, 221 oxidation, and hydrolysis rates, CDS-MIBG $\left[{ }^{11} \mathrm{C}\right] \mathbf{1}$ a remains 222 the best candidate among the three CDS-MIBG $\left[{ }^{11} \mathrm{C}\right] \mathbf{1 a}-\mathbf{c}$. In 223
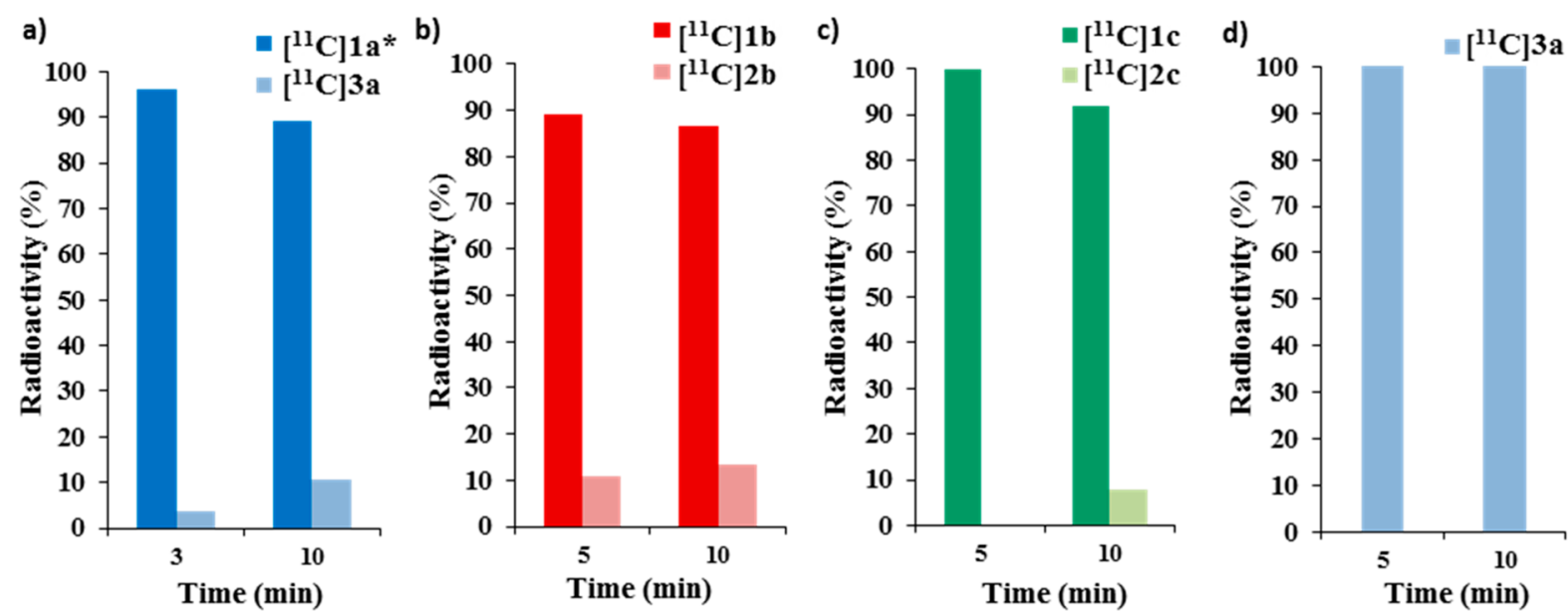

Figure 3. Percentage of the expected $\left[{ }^{11} \mathrm{C}\right]$ radioactive species in brain after injection into rat of $(\mathrm{a})\left[{ }^{11} \mathrm{C}\right] \mathbf{1 a},(\mathrm{b})\left[{ }^{11} \mathrm{C}\right] \mathbf{1 b},(\mathrm{c})\left[{ }^{11} \mathrm{C}\right] \mathbf{1} \mathbf{c}$, and $(\mathrm{d})$ $\left[{ }^{11} \mathrm{C}\right] \mathbf{1 d}$ (mean, $n=2$ for each time point). $\left[{ }^{11} \mathrm{C}\right] 1 \mathbf{a}^{*}$ results are from ref 15 . 
Scheme 5. Schematic Representation for MIBG Release from Carrier-linker-MIBG 1d

\section{Central Nervous System}

$$
\begin{aligned}
& {\left[\begin{array}{l}
11 / 12 \mathrm{C}] 1 \mathrm{~d} \\
\text { oxidation } \\
\text { (NAD } / \text { NADH) }
\end{array}\right.} \\
& \qquad
\end{aligned}
$$

MIBG release in a two-step process

Direct MIBG release

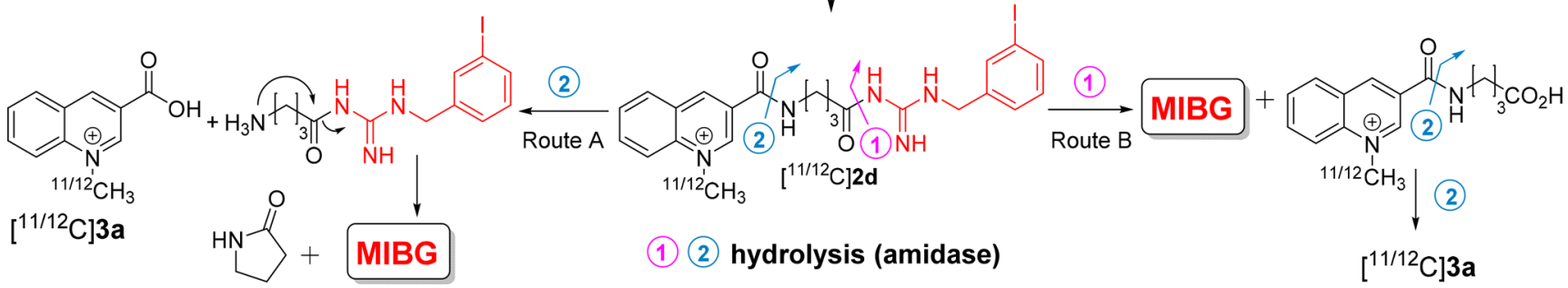

224 contrast, HPLC analyses of both brain and plasma samples at 5 $225 \mathrm{~min}$ after injection of 1,4 -dihydroquinoline $\left[{ }^{11} \mathrm{C}\right] \mathbf{1 d}$ revealed 226 the presence of only one polar radioactive compound 227 corresponding to the carboxylic acid $\left[{ }^{11} \mathrm{C}\right] 3 \mathrm{a}$ (Figure $3 \mathrm{~d}$ ). 228 These data indicate a fast in vivo oxidation of $\left[{ }^{11} \mathrm{C}\right] \mathbf{1} \mathbf{d}$ followed 229 by hydrolysis of the resulting quinolinium salt $\left[{ }^{11} \mathrm{C}\right] \mathbf{2 d}$ leading 230 to the release of carboxylic acid $\left[{ }^{11} \mathrm{C}\right] 3 \mathrm{a}$ along with the linker231 MIBG intermediate, which would undergo cyclization to 232 produce desired MIBG along with $\gamma$-lactam as byproduct. This 233 scenario depicted in Scheme 5 (route A) is backed up by the 234 fact that during the preparation of $\mathbf{8} \mathbf{b}, \mathbf{b}^{\mathbf{\prime}}$, a fast cyclization 235 process of the corresponding free amine was observed leading 236 to MIBG and $\gamma$-lactam products. At this stage, a second 237 scenario cannot be ruled out in which hydrolysis would occur 238 at the carbonyl group attached to MIBG as shown in Scheme 5 239 (route B) to release MIBG in a single step. In light of our 240 results, it might be concluded that the presence of a linker 241 between the 1,4-dihydroquinoline moiety and MIBG increases 242 notably not only the BBB passage and oxidation rate of $\left[{ }^{11} \mathrm{C}\right]$ $243 \mathbf{1 d}$ but also the release of MIBG from the carrier in the brain. 244 In this study, we successfully synthesized and labeled with 245 carbon-11 various $\left[{ }^{11} \mathrm{C}\right] \mathrm{CDS}-\mathrm{MIBG}\left(\left[{ }^{11} \mathrm{C}\right] \mathbf{1} \mathbf{b}-\mathbf{d}\right)$. We also 246 examined in vivo their potential to deliver MIBG into the 247 central nervous system. A preclinical evaluation showed high $248 \mathrm{BBB}$ permeability of the carrier-linker-MIBG $\left[{ }^{11} \mathrm{C}\right] \mathbf{1 d}$ as 249 demonstrated by the high percentage of radioactivity measured 250 in the brain, whereas the two other CDS-MIBG $\left[{ }^{11} \mathrm{C}\right] \mathbf{1} \mathbf{b}, \mathbf{c}$ 251 exhibited poor BBB passage. Once in the brain, fast oxidation 252 of the 1,4-dihydroquinoline $\left[{ }^{11} \mathrm{C}\right] \mathbf{1} \mathbf{d}$ and prompt cleavage of 253 MIBG from the resulting quinolinium salt $\left[{ }^{11} \mathrm{C}\right] 2 \mathrm{~d}$ take place 254 as evidenced by the only presence of carboxylic acid $\left[{ }^{11} \mathrm{C}\right] 3 \mathrm{a}$ in 255 brain samples after $5 \mathrm{~min}$. In light of these promising in vivo 256 profiles observed with $\left[{ }^{11} \mathrm{C}\right] \mathbf{1 d}$, this work paves the way to the 257 use of the CDS-radiolabeled-MIBG as an appealing imaging 258 tool for the study of cerebral adrenergic nerve endings within 259 the brain. ${ }^{26272829}$

\section{0 \\ ASSOCIATED CONTENT}

\section{S Supporting Information}

262 The Supporting Information is available free of charge on the 263 ACS Publications website at DOI: 10.1021/acsmedchem264 lett.8b00642.

Experimental procedures and characterization of all compounds, radiosyntheses and procedures for in vivo experiments (PDF)

\section{AUTHOR INFORMATION}

*E-mail: gourand@cyceron.fr.

*E-mail: vincent.levacher@insa-rouen.fr. ORCID $\odot$

Fabienne Gourand: 0000-0002-3585-6437

Vincent Levacher: 0000-0002-6429-1965

Author Contributions

The manuscript was written through contributions of all 276 authors. All authors have given approval to the final version of 277 the manuscript;

278

Notes

The authors declare no competing financial interest.

\section{ACKNOWLEDGMENTS}

This study was supported by a grant from CEA (Commissariat 282 à l'Energie Atomique et aux Energies Alternatives), Labex 283 IRON (ANR-11 LABX-0018-01), INSA-Rouen, Rouen Uni- 284 versity, CNRS, Labex SynOrg (ANR-11-LABX-0029), and 285 Région Normandie. D.P. was supported by a grant "CIFRE" 286 from Région Basse-Normandie and Cyclopharma laboratories. 287 A.H. was supported by a grant from Région Haute-Normandie 288 (Grant: CRUNCh 6-13).

\section{ABBREVIATIONS}

290

MIBG, meta-iodobenzylguanidine; NET, norepinephrine trans- 291 porter; BBB, blood-brain barrier; CDS, chemical delivery 292 system; SPECT, single photon emission computed tomog- 293 raphy; PET, positron emission tomography; CNS, central 294 nervous system; ADHD, attention deficit hyperactivity 295 disorder

\section{REFERENCES}

297

(1) Goldstein, D. S.; Eisenhofer, G.; Flynn, J. A.; Wand, G.; Pacak, 298 K. Diagnosis and Localization of Pheochromocytoma. Hypertension 299 2004, 43, 907-910.

(2) Cryer, P. E. Pheochromocytoma. West. J. Med. 1992, 156, 399- 301 407.

(3) Brisse, H.; Edeline, V.; Michon, J.; Couanet, D.; Zucker, J.; 303 Neuenschwander, S. Current strategy for the imaging of neuro- 304 blastoma. J. Radiol. 2001, 82, 447-54.

(4) Zhang, H.; Huang, R.; Pillarsetty, N.; Thorek, D. L.; 306 Vaidyanathan, G.; Serganova, I.; Blasberg, R. G.; Lewis, J. S. Synthesis 307 and evaluation of $18 \mathrm{~F}$-labeled benzylguanidine analogs for targeting 308 the human norepinephrine transporter. Eur. J. Nucl. Med. Mol. Imaging 309 2014, 41, 322-332. 
311 (5) Zhang, H.; Huang, R.; Cheung, N.-K. V.; Guo, H.; Zanzonico, P. 312 B.; Thaler, H. T.; Lewis, J. S.; Blasberg, R. G. Imaging the 313 Norepinephrine Transporter in Neuroblastoma: A Comparison of 314 [18F]-MFBG and 123I-MIBG. Clin. Cancer Res. 2014, 20, 21823152191.

316 (6) Hu, B.; Vavere, A. L.; Neumann, K. D.; Shulkin, B. L.; DiMagno, 317 S. G.; Snyder, S. E. A Practical, Automated Synthesis of meta318 [18F]Fluorobenzylguanidine for Clinical Use. ACS Chem. Neurosci. 319 2015, 6, 1870-1879.

320 (7) Pandit-Taskar, N.; Zanzonico, P.; Staton, K. D.; Carrasquillo, J. 321 A.; Reidy-Lagunes, D.; Lyashchenko, S.; Burnazi, E.; Zhang, H.; 322 Lewis, J. S.; Blasberg, R.; Larson, S. M.; Weber, W. A.; Modak, S. 323 Biodistribution and Dosimetry of 18F-Meta-Fluorobenzylguanidine: 324 A First-in-Human PET/CT Imaging Study of Patients with 325 Neuroendocrine Malignancies. J. Nucl. Med. 2018, 59, 147-153.

326 (8) Baulieu, J. L.; Huguet, F.; Chalon, S.; Gerard, P.; Frangin, Y.; 327 Besnard, J. C.; Pourcelot, L.; Guilloteau, D. $\left.{ }^{125} \mathrm{I}\right] \mathrm{MIBG}$ uptake and 328 release in different regions of the rat brain. Nucl. Med. Biol. 1990, 17, 329 511-514.

330 (9) Prokai, L.; Prokai-Tatrai, K.; Bodor, N. Targeting drugs to the 331 brain by redox chemical delivery systems. Med. Res. Rev. 2000, 20, $332367-416$.

(10) Bodor, N.; Buchwald, P. Barriers to remember: brain-targeting 334 chemical delivery systems and. Alzheimer's disease. Drug Discovery 335 Today 2002, 7, 766-774.

336 (11) Bodor, N.; Venkatraghavan, V.; Winwood, D.; Estes, K.; 337 Brewster, M. E. Improved delivery through biological membranes. 338 XLI. Brain-enhanced delivery of chlorambucil. Int. J. Pharm. 1989, 53, 339 195-208.

340 (12) Wu, W. M.; Pop; Shek, E.; Bodor, N. Brain-specific chemical 341 delivery systems for beta-lactam antibiotics. In vitro and in vivo 342 studies of some dihydropyridine and dihydroisoquinoline derivatives 343 of benzylpenicillin in rats. J. Med. Chem. 1989, 32, 1782-1788.

344 (13) Pop, E.; Bodor, N. Chemical systems for delivery of 345 antiepileptic drugs to the central nervous system. Epilepsy Res. $3461992,13,1-16$

347 (14) Bodor, N.; Buchwald, P. Soft Drugs in Retrometabolic Drug 348 Design and Targeting; John Wiley \& Sons, Inc.: Hoboken, NJ, 2012. 349 (15) Gourand, F.; Mercey, G.; Ibazizène, M.; Tirel, O.; Henry, J.; 350 Levacher, V.; Perrio, C.; Barré, L. Chemical delivery system of 351 Metaiodobenzylguanidine (MIBG) to the central nervous system. J. 352 Med. Chem. 2010, 53, 1281-1287.

353 (16) Gourand, F.; Ţînţ̧aş, M.-L.; Henry, A.; Ibazizène, M.; Dhilly, 354 M.; Fillesoye, F.; Papamicaël, C.; Levacher, V.; Barré, L. Delivering 355 FLT to the Central Nervous System by Means of a Promising 356 Targeting System: Synthesis, $\left[{ }^{11} \mathrm{C}\right]$ Radiosynthesis and in Vivo 357 Evaluation. ACS Chem. Neurosci. 2017, 8, 2457-2467.

358 (17) Tedjamulia, M. L.; Srivastava, P. C.; Knapp, F. F., Jr. Evaluation 359 of the brain-specific delivery of radioiodinated (Iodophenyl) alkyl360 substituted amines coupled to a dihydropyridine carrier. J. Med. Chem. $3611985,28,1574-1580$.

362 (18) Benoit, R.; Dupas, G.; Bourguignon, J.; Quéguiner, G. Facile 363 synthesis of annelated NADH model precursors. Synthesis 1987, 12, 364 1124-1126.

365 (19) Charpentier, P.; Lobregat, V.; Levacher, V.; Dupas, G.; 366 Quéguiner, G.; Bourguignon, J. An efficient synthesis of 3367 cyanoquinoline derivatives. Tetrahedron Lett. 1998, 39, 4013-4016. 368 (20) Woodman, D. J.; Davidson, A. I. N-Acylation during the 369 addition of carboxylic acids to $\mathrm{N}$-tert-butylacylketenimines and the 370 use of the reagent $\mathrm{N}$-tert-butyl-5-methylisoxazolium perchlorate for 371 peptide synthesis. J. Org. Chem. 1973, 38, 4288-4295.

372 (21) Zhang, X.-B.; Waibel, M.; Hasserodt, J. An autoimmolative 373 spacer allows first-time incorporation of a unique solid-state 374 fluorophore into a detection probe for acyl hydrolases. Chem. - Eur. 375 J. 2010, 16, 792-795.

376 (22) DeWit, M. A.; Gillies, E. R. Design, synthesis, and cyclization of 377 4-aminobutyric acid derivatives: potential candidates as self378 immolative spacers. Org. Biomol. Chem. 2011, 9, 1846-1854.
(23) Alouane, A.; Labruère, R.; Le Saux, T.; Schmidt, F.; Jullien, L. 379 Self-immolative spacers: kinetic aspects, structure-property relation- 380 ships, and applications. Angew. Chem., Int. Ed. 2015, 54, 7492-7509. 381 (24) Barré, A.; Ţînţaş, M.-L.; Levacher, V.; Papamicaël, C.; Gembus, 382 V. An overview of the synthesis of highly versatile N-hydroxysucci- 383 nimide esters. Synthesis 2017, 49, 472-483.

(25) Bohn, P.; Gourand, F.; Papamicaël, C.; Ibazizène, M.; Dhilly, 385 M.; Gembus, V.; Alix, F.; Tintas, M.-L.; Marsais, F.; Barré, L.; 386 Levacher, V. Dihydroquinoline carbamate derivatives as $\ll$ bio- 387 oxidizable $\gg$ prodrugs for brain delivery of acetylcholinesterase 388 inhibitors: [11C] radiosynthesis and biological evaluation. ACS Chem. 389 Neurosci. 2015, 6, 737-744.

(26) Jewett, D. M. A simple synthesis of $\left[{ }^{11} \mathrm{C}\right]$ methyl triflate. Int. J. 391 Rad. Appl. Instrum. A 1992, 43, 1383-1385.

(27) Mauzerall, D.; Westheimer, F. H. 1-Benzyldihydronicotinamide 393 - A model for reduced DPN. J. Am. Chem. Soc. 1955, 77, 2261-2264. 394 (28) Wieland, D. M.; Wu, J.-L.; Brown, L. E.; Mangner, T. J.; 395 Swanson, D. P.; Beierwaltes, W. H. Radiolabeled adrenergic neuron- 396 blocking agents: adrenomedullary imaging with [ $\left.{ }^{131} \mathrm{I}\right]-397$ Iodobenzylguanidine. J. Nucl. Med. 1980, 21, 349-353.

(29) Wieland, D. M.; Mangner, T. J.; Inbasekaran, M. N.; Brown, L. 399 E.; Wu, J.-L. Adrenal medulla imaging agents: a structure-distribution 400 relationship study of radiolabeled aralkylguanidines. J. Med. Chem. 401 1984, 27, 149-155. 